\title{
Re-language-ing Shakespeare for a Ugandan readership Potentials and pitfalls of translating King Lear in a Ugandan language
}

\section{James Taabu Busimba}

This article is one of the outcomes of recent research I carried out in Uganda between June and September 2014. During this period I was interested in the obtaining presences of William Shakespeare and John Ruganda in contemporary Ugandan audiences: theatres, schools, universities, cultural centers, cinema halls and the everyday readers. While interacting with Cornelius Gulere Wambi, one of my key respondents, I was pleasantly struck by his ongoing "new project" in which he was concurrently translating five drama texts from English into Lusoga, one of the major indigenous Bantu languages, very close to the rather dominant Luganda spoken in the central and southern parts of Uganda. The texts which Gulere was translating are Austin Bukenya's The Bride (as Omugole), Wole Soyinka's The Trials of Brother Jero (as Ebikemo by'Owoluganda Yero), Sophocles' Antigone (as Nantamegwa), Francis Imbuga's Betrayal in the City (as Nkwe mu Kibuga) and William Shakespeare's King Lear (as Kyabazinga Mukama). Overall, these plays are an innovative intervention in the literary realities invigorated in Lusoga expression and adorned in new language and diction. However, my research interests directed me to Shakespeare's King Lear translated as Kyabazinga Mukama, particularly in the context of providing further alternative writings and readings of Shakespeare in a contemporary African cultural space. ${ }^{1}$ By the time of drafting this paper, Gulere Wambi had translated King Lear's Act 1 to a tentative conclusion. ${ }^{2}$ The translation is based on the free online edition of King Lear, published by PSU. So far, his translation of King Lear from English to Lusoga is clearly a project in re-language-ing or, even more inclusively, an exercise in reconfiguring Shakespeare. Gulere's is a relanguage-ing which in itself is a form of editing and at the same time a specific mode of presenting Shakespeare to both the new and qualified Lusoga readers. ${ }^{3}$

In this discussion I found two concepts helpful: Taban lo Liyong's observation that translation is a sine qua non in securing African languages and literatures in the global arena of the twenty first century and beyond; and Charles Cantalupo's positing that only when two or more languages meet do real meanings emerge. ${ }^{4}$ That the language of expression in a translation plays a major role in the transmission of a new message in a new way is perhaps a given. However, when two languages meet in a translation, the resultant text seems to perform more tasks than convey what is in the original text, if ever the original can be found. It may be of help to remind ourselves that Shakespeare himself created new meanings from texts - some of which were not in English - through the act of Englishing them. Similarly, we may say that what Gulere does in the process of translating King Lear is to Lusogafy the play in the context of two languages meeting and generating new 
meanings for the readers, producers, performers and theatre audiences. ${ }^{5}$

Aware that Gulere Wambi's translation is still in progress and that many changes in the embryonic drafts are to be expected along the way, I reflect on the appellations he assigns to the principal figures in his translation of King Lear available so far. In the nomenclature of the stage persons and imagery of Kyabazinga Mukama Gulere Wambi inscribes signposts suggestive of how his translation is to be categorised, appreciated and analysed. Both the initiated critic and everyday reader have to grapple with different challenges of interpreting and meaning making in the new text. The naming of people, places and things as well as the use of imagery is localized within the Lusoga language context(s), thus raising some conceptual challenges especially with regards to contextualisation, categorization and authorship. The following illustrations are worth considering.

To the ordinary speaker or reader of Lusoga the title Kyabazinga Mukama is not strange because "Kyabazinga" is the titular head of the traditional chiefdoms of the Basoga people. ${ }^{6}$ More importantly, the appellation of "Mukama" is a reconfiguration of the mythical Mukama, progenitor of the Basoga ethnic group. I contend that, overall, Gulere Wambi reconfigures Lusoga mythology and other aspects of his people's traditional folklore in his re-language-ing of King Lear, in a strategy he refers to as a transformation of the play in order to fit into the socio-linguistic milieu of Lusoga discourse. The qualified reader who makes a distinction between the socio-cultural milieu of both the
English King Lear and the Lusoga Kyabazinga Mukama is likely to feel that adapting the play to Busoga's history can be satisfactory and appealing. "Kyabazinga," for instance, would rouse imaginations of a supreme earthly mortal in a not-so-present a time, and therefore one who is at liberty to exercise any of his royal rights and prerogatives even if it is to divide his kingdom and devolve his powers to his offspring. As for the new reader, well, Kyabazinga Mukama is a play which can be read and enjoyed normally in the here-and-now. At the time of writing this paper the Basoga were engaged in a series of installation and noninstallation of the Kyabazinga. It is therefore interesting to note that Kyabazinga Mukama is in conversation with the contemporary sociopolitical history of the Basoga people

The reconfigurations of the principal stage persons in Gulere Wambi's translation provide a site for exploring the potential and pitfalls in the Kyabazinga Mukama translation. For ease of reference, I present some of the names of the stage persons in King Lear as well as their corresponding Lusoga equivalents in Kyabazinga Mukama in the included table (Table 1).

First, it can be argued that maintaining the English names of the source text by simply Lusogafying them easily achieves the unity of the text, especially in terms of local pronunciation as is the case with "Fulansi" and "Olubaane". Perhaps some Lusoga readers have heard about a country called France and they can easily 


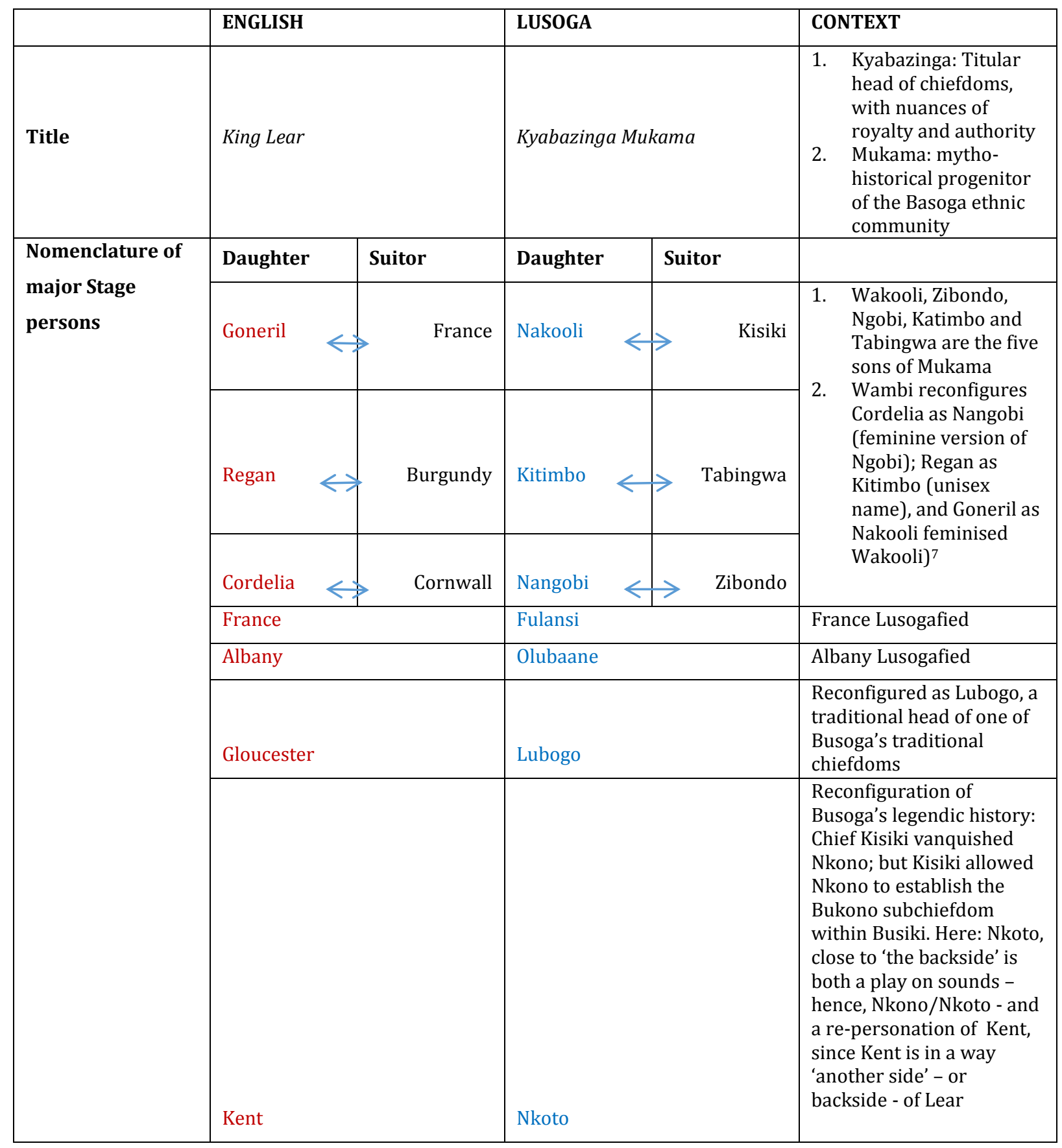

Table 1 Correspondences of names

relate to this nomenclature. The alternative could possibly be to assign a traditional name of one of the territories which have borders with Busoga - such as Buganda to the west or Busamya to the east. Such a strategy, in the translation could move the readers nearer and closer to what they know and perhaps the relationship would make much sense to them. The realities that seem to have influenced the source text, namely the devolution of political 
authority and control can also be traced in the Basoga culture. Granted, but I think that the strategy would inevitably leave gaps in the desired communication. Therefore, adapting the play to Busoga's in-house history would perhaps be more satisfactory and more appealing. According to Gulere Wambi:

Cordelia, Regan and Goneril are three of Mukama's five children namely Wakooli of Bukooli who was the first born, Zibondo of Bulamoogi, Ngobi of Kigulu, Tabingwa of Luwuka and Katimbo of Bugabula. From these five, Cordelia would be Ngobi/Nangobi of Kigulu, Regan is Katimbo/Kitimbo of Bugabula, and Goneril is Wakooli/Nakooli of Bukooli. Their suitors France, Burgundy, and Cornwall are, Kisiki of Busiki, Tabingwa of Luwuka and Zibondo of Bulamoogi respectively. ${ }^{8}$

Changing the English names as presented in King Lear to the names of Busoga's Chiefdom epithets easily achieves the goal of localisation and what Gulere Wambi calls total transformation of the text. Demonstrably, the strategy of localisation makes the play more informative and culturally engaging in the target language through appropriate equivalences in the nomenclature of the stage persons. The expressive traces in the historical relationships between Busoga chiefs, manifested in their infighting for the throne of Kyabazinga which is evident even in contemporary Uganda, makes the translation meritable in the context of the Lusoga reader of Kyabazinga Mukama. After all, a fragment of Busoga historiography has it that Chief Kisiki conquered Chief Nkono but allowed the latter to establish Bukono sub-chiefdom within the larger Busiki chiefdom. Hence, for instance, presenting Kisiki as the equivalent of France who allows his captors to reign within the same larger kingdom is therefore not farfetched. One can argue that Kyabazinga Mukama is in itself a true literary experience for the Lusoga speaking audience; particularly in the sense that the translations reverberates with the realities that seem to influenced the culture of the Basoga eve in the contemporary geotemporal space.

Of course communicating the meaning of a source language text by means of an equivalent target language involves interpreting. What Gulere Wambi does is to localise the translation of King Lear and adapt the physical and linguistic environment of Busoga to the interests of his target audience. Where horses and chariots are mentioned in King Lear, bulls, donkeys and bicycles familiar to Busoga's transport system are used in Kyabazinga Mukama. Some more examples may demonstrate this localisation further.

Where Lear says to Cordelia "Let it be so; thy truth, then, be thy dower" (1.1), Mukama says to Nangobi:

Kale kibe kityo, obutuufu bwo mperano bube omwandu gwo

(May it be so, your truth shall be your inheritance) ${ }^{9}$

Within the Lusoga context "omwandu" is inheritance, yes, but received by a wife only after she is widowed. Invoking the nuances of death in the "omwandu" reference creates a new image of 
Lear in the person of Kyabazinga Mukama, for by dispossessing himself of the kingdom, he renders himself dead in terms of political authority. The variance between dower as bequest to daughter and "omwandu" as to a widow helps not only to locate this decisive moment in the play, in the context of Busoga realities but creates another level of possible interpretation, especially on the part of the reader who already knows something about King Lear. Other expressions, all from Act One and whose equivalent English translations are my own attempts at translation, may help amplify some aspects of the Lusoga context of Kyabazinga Mukama.

Regan: Sir, I'm made of the self-same metal as my sister...

Nakooli: Ndi ng'enigha eighaali eyo... (Lusoga image, perhaps equivalent to "I'm as strong as the centre-piece of a bicycle")

Lear: Here, I disclaim all my paternal care...

Mukama: Nkughandula okuva mu kino... (Literary "I spit you from this matter")

Lear: Come not between the dragon and his wrath

Mukama: Tiweleka ghagati gha kitugha muyigo n'omuyigo gwe (Remain not between the trap and the animal it is meant for)
Lear: The bow is bent and drawn, make from the shaft...

Mukama: Omutego gweghese era gwesise...(The trap is about to snap)

Lear: Now, by Apollo...

Mukama: Ku lwa Isegya (Isegya is the Lusoga approximation of the god of "healing")

Lear: 0, vassal! Miscreant!

Mukama: ighe omwidu omusirusiru... (You! Foolish slave...)

Lear: Hear me, recreant!

Mukama: Mpuliriza ighe munanfuusi! (Listen you hypocrite! Among the Basoga - like in many other societies hypocrisy is like leprosy in the context of human dealings)

Kent (to Cordelia): The gods to their dear shelter take thee, maid...

Nkoto (to Nangobi): Ba katonda bo bakubambatire mu nsiisira dhaibwe... (May your gods comfort you in their huts...)

Burgundy (to Lear): Most royal majesty...

Tabingwa (to Mukama): Isebantu Nsolonkambwe... (Father of the people, fierce animal: perhaps reference to the lion, a symbol of royalty in many cultures of Africa) 
But does this localisation in the translation not completely drain the play of its historicity? It may, if historicity is conceived of as some static entity. If historicity is a continuum of experiences, Kyabazinga Mukama constitutes its own variety of historicity as a "new" literary text especially because of the way the translation links the past and the present although not every reader of Kyabazinga Mukama is required to or must have knowledge of the source text, King Lear. As we would expect, the words on the pages of Kyabazinga Mukama or those of actors if the play is acted on stage will "do things" in the spirit of John Austin in a variety of ways to both text and stage reader. In such a context, Gulere Wambi's translation, ongoing as it is, occasions its own self-sustaining historicity, in the sense that Kyabazinga Mukama links the present and the past in the localisation of the nomenclature of the stage persons and the imagery as rendered in the translation.

In a way Gulere's act in the translation of King Lear, if only coincidental to the times, factors significantly into contemporary African political behaviour. We may need no reminder to realise that in many parts of Africa it is almost an offense to even think of a reigning head of state voluntarily relinquishing political power. In localizing Lear who voluntarily relinquishes power - but wants to retain the privileges that go with political power at the same time - Gulere slaps the faces of African rulers to whom voluntarily relinquishing political authority is something of a taboo. Therefore, although Gulere Wambi's primary motivation for translating the text is essentially educational, his translation of King Lear at the time he does so seems to have some deep political implications in the context of contemporary Africa. ${ }^{10}$ Perhaps Gulere is performing a political act unconsciously. From a literary perspective, the readers of Kyabazinga Mukama are able to interact experientially with a defining theme in their contemporary sociopolitical environment. In so causing this interaction, the translation can be interpreted as a both a disruption of the political order and an invitation to rethink the very notion of voluntarily relinquishing power in our assumed democratic states. Gulere's re-language-ing of King Lear, read politically, can be a significant addition - and alternative discourse - the democratic debate in much of Africa.

Broadly, therefore, Gulere's translation of King Lear plays the role of a bridge carrying ideas across cultures and interconnecting specific English as well as universal human values as enacted in the source text with those experienced in Kyabazinga Mukama. If, along the way, his translation may involve false equivalents, false friends and false cognates as is usually said of amateur translators, one hopes that the creation of Kyabazinga Mukama as an artistic text in itself can work as a redeeming factor. Perhaps the appreciation and artistic enjoyment of the new text actually at hand is more worthwhile than an exercise in mistake spotting. If in the new text - the translation - the stage persons of Mukama and Lear are in conversation; Gulere Wambi and Shakespeare are artistically whispering to each other; Uganda and England are thriving in the new, actual and virtual literary environment; and if I am gaining more wisdom about a number of worthwhile questions relating to Shakespeare's presence in 
Uganda; and the broader dynamics Shakespeare in configuration, I think Gulere Wambi's configuration of King Lear in translation into Lusoga will afford us an additional arena for sharing both local and universal experiences engaged in King Lear as well as in Kyabazinga
Mukama. Inevitably, Gulere Wambi's Kyabazinga Mukama will fracture many of our hitherto held notions about editing and performing Shakespeare in the twenty first century and beyond.

\section{Works Cited}

Breitinger, Eckhard, ed. Uganda: the Cultural Landscape. Kampala: Fountain Publishers, 2000.

de Grazia Margaret and Stanley Wells, Eds. The New Cambridge Companion to Shakespeare. Cambridge: Cambridge University Press, 2013.

Dipio, Dominica, Lene Johannessen and Stuart Sillars, eds. Performing Change; identity, ownership and tradition in Ugandan Oral Culture. Oslo: Novus Press 2009.

Evans, Jessica and Stuart Hall. Eds. Visual Culture: the Reader. London, Thousand Oaks, New Delhi: SAGE Publications, 1999.

Giddens, Eugene. How to Read a Shakespearean Play Text. Cambridge: Cambridge University Press, 2011. Jane Plastow. "Shakespeare in and out of Africa". African Theatre 12, edited by Martin Banham et. al. James Currey, 2013.

Kelly, Dorothy. A Handbook for Translator Trainers, A Guide to Reflective Practice. Manchester and Northampton: St Jerome Publishing, 2005.

Kuhiwczak Piotr and Littau Karin. Eds. A Companion to Translation Studies. Clevedon, Buffalo, Toronto: Multilingual Matters Limited 2007.

Lefevere, Ander. Translating Literature: Practice and Theory in a comparative Literature context. New York: Modern Language Association of America, 1992

Maguire, E. L. Studying Shakespeare: A Guide to the Plays. Blackwell Publishing, 2004.

Meisel, Martin. How Plays Work: reading and performance. Oxford: OUP, 2007

Myklebost, Svenn-Arve. Shakespeare in Configuration: Models, Comics and Manga. PhD Dissertation Bergen: University of Bergen, 2012.

Richard Proudfoot, Ann Thompson and David Scott Kastan, Eds., Arden Shakespeare Complete Works. Revised 2001.

The Tragedy of King Lear, The Electronic Classics Series 1997 - 2013; edited by Jim Manis, PSU-Hazleton, PA. 
${ }^{1}$ In his view, Gulere Wambi claims that what he does in the process of translating King Lear into Lusoga is an exercise in transformational translation. He refashions King Lear and locates it in the Lusoga socio-historical context; in a manner which Michel Garneau would call tradaptation.

2 The exercise of translating King Lear was in its embryonic phase by the time of preparing this paper. The source text is The Tragedy of King Lear; The Electronic Classics Series 1997 - 2013, edited by Jim Manis, PSU-Hazleton, PA. The edition has page and not line numbers

3 I borrow the terms "new" and "qualified" reader from Stuart Sillars. For Sillars, what we usually refer to as the ordinary reader is a new reader, while the reader who approaches a text with specific creteria is qualified; qualified to perform a certain variety of reading. It is possible to estimate that the qualified reader has inbuilt limitations when it comes to enjoying the text. See Sillars Stuart. The Illustrated Shakespeare, 1709-1875 (Cambridge: Cambridge University Press, 2008), p. 24.

4 The two scholars made these remarks at the opening of the International Conference on African Languages and Literatures which took place at the Institute of African Studies Kenyatta University; August 6th - 8th, 2014

5 In the Lusoga language, Busoga denotes the geographical territory; Basoga are the traditional inhabitants of Busoga and Lusoga is their language. I borrow from English morphology to designate Gulere Wambi's act of translation as a variety of Lusogafying King Lear.

6 The Basoga people constitute about 9\% of Uganda's population. See Uganda Bureau of Statistics (2002), “The 2002

Uganda Population and Housing Census, Population Composition," October 2006, Kampala, Uganda, p.35.

"Kyabazinga" is the traditional title of the supreme ruler of the Basoga, while "Mukama" doubles as "Lord" and "Progenitor" of the Basoga ethnic community.

${ }^{7}$ Quoted from Wambi Gulere C. "Challenges of Translating Literature from English to an African Language”, paper presented at Conference on African Languages and Literatures which took place at the Institute of African Studies Kenyatta University; August 6th - 8th, 2014; p.12

${ }^{8}$ op. cit. p.12. The Basoga people, like many African societies, are a patriarchal community. Hence, in order to come closer to the Lusoga readership, Gulere rehashes the socio-linguistic context of Goneril, Regan and Cordelia and locates the female stage persons within the Lusoga context of partible inheritance, which actually borders on primogeniture.

${ }^{9}$ I find it interesting that in this presentation I am also engaged in the exercise of translating form a translation! ${ }^{10}$ As I write this paper, Mr Museveni the President of the Republic of Uganda, for instance, has been in power since January 1986. On $15^{\text {th }}$ December 2014, the delegates' conference of the ruling National Resistance Movement (NRM) party revised some amendments in the party constitution, amendments that effectively invested even more political power in the person of the president. Although Mr Museveni celebrated his 70 th birthday on 14t September 2014, there was no evidence at the delegates' conference that he is about to relinquish power. Of course, there is the counter argument that he wields power form a democratic process, that of the NRM delegates' conference. See Daily Monitor 15th September 2014; New Vision, The Observer, Daily Monitor newspapers 17th December 2014. 